\title{
Laboreal
}

Volume $3 \mathrm{~N}^{\circ} 2$ | 2007

Trabalho infantil

\section{Elaboración, estructuración y realización de gestualidad de trabajo : los gestos en el ensamblaje de automóviles y el encofrado de los puentes de autopista}

Elaboração, estruturação e realização de "gestualidade" de trabalho : os gestos na montagem de automóveis e na cofragem de pontes de auto estrada Elaboration, structuration et réalisation des gestuelles de travail : les gestes dans l'assemblage automobile, et dans le coffrage des ponts d'autoroute

Elaboration, structuring and realization of work "gesturality" : the gestures in car assembly and in the moulding of highway bridges

\section{Karine Chassaing}

\section{OpenEdition}

Journals

Edición electrónica

URL: http://journals.openedition.org/laboreal/12632

DOI: 10.4000/laboreal. 12632

ISSN: 1646-5237

Editor

Universidade do Porto

\section{Referencia electrónica}

Karine Chassaing, «Elaboración, estructuración y realización de gestualidad de trabajo : los gestos en el ensamblaje de automóviles y el encofrado de los puentes de autopista », Laboreal [En línea], Volume $3 \mathrm{~N}^{0} 2$ | 2007, Publicado el 01 diciembre 2007, consultado el 24 septiembre 2020. URL : http:// journals.openedition.org/laboreal/12632; DOI : https://doi.org/10.4000/laboreal.12632

Este documento fue generado automáticamente el 24 septiembre 2020.

\section{(c) (†) 8}

Laboreal está licenciado com uma Licença Creative Commons - Atribuição-NãoComercial 4.0 Internacional. 


\section{Elaboración, estructuración y realización de gestualidad de trabajo : los gestos en el ensamblaje de automóviles y el encofrado de los puentes de autopista}

Elaboração, estruturação e realização de "gestualidade" de trabalho: os gestos na montagem de automóveis e na cofragem de pontes de auto estrada Elaboration, structuration et réalisation des gestuelles de travail : les gestes dans l'assemblage automobile, et dans le coffrage des ponts d'autoroute Elaboration, structuring and realization of work "gesturality" : the gestures in car assembly and in the moulding of highway bridges

Karine Chassaing

\section{REFERENCIA}

Chassaing, K. (2006). Elaboration, structuration et réalisation des gestuelles de travail : les gestes dans l'assemblage automobile, et dans le coffrage des ponts d'autoroute. Thèse d'Ergonomie, Paris : Laboratoire d'Ergonomie, CNAM.

\section{NOTA DEL EDITOR}

Manuscrito recibido en : octubre/2007

Aceptado tras peritage en : noviembre/2007 


\section{Los gestos en el trabajo, cuestión de actualidad}

1 El principal propósito de esta tesis es poner de relieve la organización compleja de los gestos de trabajo que se aprenden sobre la marcha. A nuestro entender, esta organización es compleja porque es resultado de una elaboración a lo largo de la vida y de los itinerarios profesionales, porque la estructuran invariantes operatorias propias a los gestos y, por último, porque se practica en contextos laborales que la orientan.

2 Elegir este tema para un trabajo de investigación de ergonomía supone, para empezar, reparar en su pertinencia social. El gesto se estudia desde hace tiempo en la fisiología laboral y en ergonomía. El objeto de nuestra introducción es mostrar que el gesto, así como la experiencia del gesto, tienen importancia social. Algo que merece ser reafirmado porque, en cierto modo, el trabajo manual ha perdido visibilidad social. Las evoluciones del trabajo no implican "perder" el trabajo manual (Volkoff, 2005). La existencia misma de una patología del gesto, o sea los TME, lo demuestran a las claras. Es por ello útil reflexionar sobre la construcción de los gestos para prevenir los TME. Por su lado, la evolución demográfica, con las jubilaciones masivas que cabe esperar, refuerza el interés de estudiar la relación entre experiencia y gestos del trabajo desde el prisma de la transmisión del saber práctico.

\section{El gesto de trabajo, complejo y construido}

Prolongando una literatura científica de distintas disciplinas, como la fisiología, la neurofisiología, la psicología y la ergonomía, comprender e identificar la complejidad de los gestos parece legítimo para afinar la comprensión de su construcción. Para ello, clasificamos esta complejidad según cuatro características del gesto :

- “el gesto es algo que se compone » : con esta expresión resumimos la idea de que el gesto necesita una actividad sensorial, cognitiva y motora que implica procesos de percepción tomar una decisión -, acción y una estructura de coordinación (Berthoz, 1997);

- " el gesto se coloca » : es intencionado y se orienta hacia obje-

- tivos diferentes : hacia el sistema, hacia uno mismo y hacia los demás (Gaudart \& WeillFassina, 1999) ;

- "el gesto se sitúa » : en este nivel, recordamos que la actividad de trabajo, objeto de estudio de la ergonomía, está situado. Esta constituye una de las condiciones de la actividad y, por lo tanto, de los gestos realizados en el trabajo (Daniellou, 1998);

- "el gesto se construye » : por último, y éste es un tema predominante en nuestra tesis, sostenemos la idea de que el gesto es producto de una historia, un pasado, y se desarrolla sin cesar. Examinamos el papel de la experiencia en este desarrollo, al tiempo que tomamos en cuenta los márgenes del sistema que permiten más o menos ese desarrollo (como favorecen más o menos la realización del gesto mismo). La experiencia se contempla aquí como recurso para desarrollar un gesto (Gaudart, 2000).

\section{Propuesta de modelo centrado sobre la gestualidad}

Las características citadas describen las múltiples dimensiones del gesto (sicológica, biomecánica, fisiológica, organizativa...). Pero nosotros renovamos estos planteamientos insistiendo sobre la estructuración de los gestos para completar esta 
idea de complejidad y proponiendo para ello un modelo centrado sobre el concepto de gestualidad. Se trataría de conjuntos estructurados y previamente constituidos. Forman "armaduras" relativamente estables a corto plazo y utilizables en situaciones diferentes. Se elaboran y remodelan por efecto de la experiencia. Consideramos la gestualidad como un registro de competencias específicas, o sea, propias al uso del cuerpo e íntimamente relacionadas con el polo "yo" de la actividad profesional. Es algo personal, sobre todo porque los usos del cuerpo son individuales. La noción de competencias, tal como la define De Montmollin (1984), es más general que la de gestualidad: las competencias no tienen que ver sólo con los gestos. Por eso hemos decidido tratar en nuestra investigación sobre gestualidad para hablar de esas competencias propias del cuerpo y de los gestos en el trabajo.

\section{Métodos de análisis de la gestualidad}

5 Hemos analizado gestos de trabajo en dos sectores de actividad distintos : el automóvil, que, por una parte, forma la destreza para las actividades de montaje de motores, y, por otra, actividades de soldadura automática en un taller de chapa ; y la ingeniería civil, con actividades de encofrado de puentes de autopista. Son tres situaciones diferentes desde el punto de vista de los márgenes de maniobra, la variabilidad en la situación y el grado de repetición de los gestos. Así, la confrontación de estas tres situaciones nos lleva a plantear también las relaciones entre los márgenes de maniobra y la experiencia gestual, así como la elaboración de los gestos y los métodos que hay que instaurar para comprender este desarrollo. Insistimos en el componente "realizado" del gesto y en las condiciones de realización, tanto desde el punto de vista de las cortapisas como de los factores que favorecen esta puesta en práctica. Hemos conservado una línea metodológica común para las tres situaciones, pero ha habido que adaptar los métodos a cada una. Una posibilidad consiste en analizar los gestos que se repiten en cada situación para poder establecer comparaciones entre ellas. Hemos realizado montajes de vídeos de un gesto, seleccionado previamente con los análisis de la actividad, para organizar después auto-confrontaciones individuales con los operarios.

\section{La gestualidad : su elaboración y su realización en contextos diferentes}

6 Mostramos que los operarios elaboran principios de utilización de su cuerpo en el trabajo que les hacen ser más eficiente y eficaces. Estos principios son los componentes de la gestualidad, son propios a una acción y pueden transferirse de una situación a la otra. Permiten que el operario prepare su gesto y lo ajuste a la situación del momento. Los principios de base identificados en las situaciones de chapistería e ingeniería civil traducen la existencia de reglas de acción propias al uso del cuerpo. Son de diferente naturaleza. En la situación de la automoción, están más relacionadas con la salud, la atenuación y la reducción del dolor. Por ejemplo, con el principio : "repartir la fuerza por el cuerpo", el operario busca puntos de apoyo en el cuerpo para equilibrar la fuerza, hacer trabajar todo el cuerpo. Este es el caso de un operario que utiliza su cadera además de sus dos brazos para colocar la pinza soldadora en su sitio. En la situación de ingeniería civil, estos principios están más relacionados con la utilización de las informaciones sensoriales, tanto más diversas cuanto más experiencia se tiene 
con la tarea. Como, por ejemplo, "Escuchar el canto de la mariposa", principio que recurre a referencias auditivas. Cuando el sonido de la tuerca mariposa que se está martilleando se hace agudo, significa que la tuerca está suficientemente apretada. Por otra parte, están relacionadas con reglas de acción del tipo "si ..., entonces" que permiten vérselas con la diversidad de contextos. Por ejemplo, si el hormigón está demasiado seco, entonces hay que forzar más con la llana y pasar más veces para que la superficie quede bonita y derecha.

7 La gestualidad pertenece a la misma clase de actividad y no a un contexto dado. Al analizar la experiencia de los operarios se puede comprender su origen, tomar en consideración el pasado del operario e identificar el papel de situaciones anteriores. La gestualidad se construye a partir de enseñanzas que se aprenden con esas situaciones, que hemos dividido en cuatro orígenes según los cuatro modos de adquisición de la experiencia :

- Experiencia originada por la práctica profesional (actual o pasada);

- Experiencia originada por la práctica extra-profesional ;

- Experiencia originada por la práctica de otros ;

- Experiencia originada por el conocimiento de uno mismo y de sus límites.

8 Los resultados obtenidos están muy marcados por los modos de organización que prevalecen en tal o cual medio profesional. Es necesario hasta qué punto consiguen los operarios regular su actividad en las situaciones. En los márgenes de maniobra que concede la organización del trabajo es donde se expresa y construye esta experiencia gestual, a partir de prácticas reflexivas. En el ensamblaje de automóviles, la gestualidad resiste frente a la normalización del trabajo. La desafían dos herramientas preceptivas : la formación de la destreza y las fichas de operaciones estándar. Proponemos, así pues, una racionalidad alternativa a la de la normalización, al tiempo que hacemos hincapié en la imposible transcripción de los gestos en procedimientos estándar. En la ingeniería civil, más caracterizada por la fuerte variedad de entornos y por la preeminencia de una cultura del oficio, recalcamos más la estructuración y el desarrollo de gestualidades en un contexto de transmisión del saber hacer. En este caso, la gestualidad permite arreglárselas con la diversidad del contexto, al tiempo que ésta se convierte en recurso para que la gestualidad se enriquezca y se transmita.

\section{Pistas de acciones posibles}

A nuestro parecer, nuestros resultados contribuyen a proponer pistas para la transformación y la acción en tres direcciones por lo menos :

- Valorar las aptitudes manuales en oficios poco cualificados y en un contexto industrial que tiende a la racionalización. Se trataría de enriquecer los argumentos de los ergónomos frente a los modelos de la normalización ;

- Prevenir los TME, ya que las reflexiones sobre la construcción de los gestos (o las cortapisas que se le ponen) ampliarían la gama de las acciones posibles sobre la organización del trabajo, los márgenes de maniobra potenciales, la rotación en los puestos o la formación;

- Y, por último, la transmisión del saber profesional en el trabajo manual : tanto desde la perspectiva de reajustar la organización del trabajo (por ejemplo, que sea posible poner en común la práctica, desarrollar prácticas reflexivas), como desde la de enriquecer los programas de formación. 


\section{BIBLIOGRAFÍA}

Berthoz, A. (1997). Le sens du mouvement. Ed. Odile Jacob. Paris. 345p.

Daniellou, F. (1998). Une contribution nécessaire au recensement des " Repères pour affronter les TMS ». In Bourgeois, F. TMS et évolution des conditions de travail. Etudes et Documents. ANACT. $35-46$.

Gaudart, C. (2000). Conditions for maintaining ageing operators at work - a case study conducted at an automobile manufacturing plant. Applied Ergonomics, vol. 31, $\mathrm{N}^{\circ}$ 5, pp. 453-462.

Gaudart, C. \& Weill-Fassina, A. (1999). L'évolution des compétences au cours de la vie professionnelle : une approche ergonomique. Formation Emploi, $\mathrm{N}^{\circ}$ 67, pp. 47-62.

Montmollin, M. (de) (1984). L'intelligence de la tâche. Eléments d'ergonomie cognitive. Eds Peter lang. Berne.

Volkoff, S. (2005). L'ergonomie et les chiffres de la santé au travail : ressources, tensions et pièges. Toulouse, Éditions Octarès.

\section{AUTOR}

\section{KARINE CHASSAING}

Centre d'Études de l'Emploi / CREAPT 29, Promenade Michel Simon, 93166 Noisy-Le-Grand Cedex karine.chassaing@wanadoo.fr 